\title{
A Theory and Tools for Collaborative Demand-to-Supply Management in the SCM Age
}

\author{
Akihiko Hayashi \\ The University of Electro-Communications \\ 1-5-1, Chofugaoka, Chofu, Tokyo, 182-8585, JAPAN \\ Email: ahayashi@se.uec.ac.jp \\ Nobuaki Ishii* \\ Bunkyo University \\ 1100, Namegaya, Chigasaki, Kanagawa, 253-8550, JAPAN \\ Email: ishii@shonan.bunkyo.ac.jp \\ Masayuki Matsui \\ The University of Electro-Communications \\ 1-5-1, Chofugaoka, Chofu, Tokyo, 182-8585, JAPAN \\ Email: matsui@se.uec.ac.jp
}

\begin{abstract}
In recent years, collaborative demand-to-supply management, which strategically supplies products to the market in order to maximize profit, has played a critical role in establishing a sustainable company. However, the sales function and the production function do not always work together for profit optimization. In most cases, the sales function is responsible for maximizing sales. On the other hand, the production function is responsible for minimizing production cost. In the SCM age, this situation causes production of excess inventory as well as long order fulfillment time. For the collaboration of both functions, a strategic demand-tosupply map has been developed. The strategic map consists of a row and a column indicating the demand speed and the smoothing factor for demand forecasting. This paper presents a theory and a planning tool, called the planner, for collaborative demand-to-supply management based on the strategic map. The planner consists of demand forecasting, aggregate planning, the strategic map, the scheduler, and progressive analysis. The effectiveness of the planner is demonstrated with a numerical example. In addition, this paper shows that the planner is a useful tool for staff in the sales department and the production department for training or understanding collaborative demand-to-supply management. This paper also presents the potential areas of future research and development of collaborative demand-to-supply management and the planner.
\end{abstract}

Keywords: collaborative demand-to-supply management, aggregate planning, strategic map, production scheduler, sustainable company, progressive analysis

\section{Introduction}

In the so called "mass-production and massconsumption age," because of long product life cycle and increasing demand, most companies recognize inventory as a valuable corporate asset. In such a situation, maintaining a balance between the demand plan and the supply plan in order to avoid excess inventory and stock shortage has not been a critical issue. Strong demand and long product life cycles were able to hide demand-to-supply management problems in the past.

* Corresponding Author 
However, today's competitive and unpredictable market requires shortened product life cycles and increased product variety. Therefore excess production which counters market demand creates excess inventory that requires disposal cost in order to be put it into the correct inventory level. In the Japanese beverage industry, for example, each company introduces approximately 100 new products into the market every year. However, only two to three products remain in the market the following year. The inventory of out-of-market products can be dead stock, which is considered a nonperforming asset. In this market situation, companies have gradually recognized inventory reduction as a management issue to increase profit. Reduction of excess inventory, however, can cause stock depletion and, therefore, fewer sale opportunities.

Under such circumstances, Supply Chain Management (SCM) has spread widely since the 1990's. SCM is defined by Simchi-Levi et al. (2007) as follows: "Supply chain management is a set of approaches utilized to efficiently integrate suppliers, manufactures, warehouses, and stores, so that merchandise is produced and distributed at the right quantities, to the right locations, and at the right time, in order to minimize systemwide costs while satisfying service level requirements." One of the goals of SCM is to improve the return on assets, which can be attained by reducing inventory as well as by increasing sales opportunity. The successful implementation of SCM requires collaborative decision making among different functions, such as sales, production, distribution, retail, and so on. (In this paper, a function refers to a part or a division in a company.)

In most cases, however, each function has a different goal, and therefore each function's strategy to attain each goal does not always results in optimization of profit. The traditional sales function's strategy and the production function's strategy especially tend to interfere with each other in today's market situation. The sales function adopts a strategy to increase sales and, therefore, requests that products be supplied based on the highest possible demand forecast. This is a reasonable strategy for the sales function to minimize sales loss because of stock shortage and maximize sales volume. On the contrary, the production function adopts a strategy to minimize production cost.
Therefore the production function tends to produce products in larger lot sizes. Larger lot size production can cause excess inventory levels as well as stock shortages under situations of sudden demand changes, because production with a long lead time cannot respond quickly to demand changes. A simplified mechanism of excess inventory and stock shortage under non-collaborative strategies of both functions is depicted in Figure 1.

As stated above, maximization of profit cannot always be attained based only on the sales function strategy or based only on the production function strategy, in which both strategies are created independently for achieving each respective function's goal. It is obvious that both sales and production functions need collaborative work for creating a strategy to maximize profit. Namely, most companies have recognized that collaborative demand-to-supply management, which strategically supplies products to the market based on a collaborative strategy with the sales function and the production function in order to maximize profit, is critical for implementing successful SCM and for establishing a sustainable company in today's market situation (Cyber Concurrent Management Research Group, 2004). (In this paper, collaborative demand-tosupply management is also called demand-to-supply management hereafter. In addition, strategy indicates a set of parameters to make a collaborative demand-tosupply plan, including a sales plan and a production plan.)

In demand-to-supply management, both the sales and the production functions work together to make a demand-to-supply plan. In this paper, we propose steps and mechanisms for making a demandto-supply plan to support demand-to-supply management. In addition, we developed PC-based decision support software called the demand-tosupply management planner. (The demand-to-supply management planner is hereafter called the planner.) In this paper, we explain a model of demand-to-supply management and process steps of the planner. A numerical example of demand-to-supply management using the planner is demonstrated. In addition, we apply the planner as a tool for training and education to implement demand-to-supply management successfully in practice. 
Because the collaborative work of sales and production functions for making a demand-to-supply plan is a relatively new practice in most companies, it is necessary to develop training and education systems for educating staff who understand the importance of collaboration and who also have skills necessary for collaborative work. From this background, we propose an education system for demand-to-supply management. In this paper, we describe the system as well as evaluate a trial class which applied the system to graduate students. Finally, we propose future research and development topics on demand-tosupply management in the SCM age.

Figure 1. A simplified mechanism of excess inventory and stock shortage under non-collaborative strategies

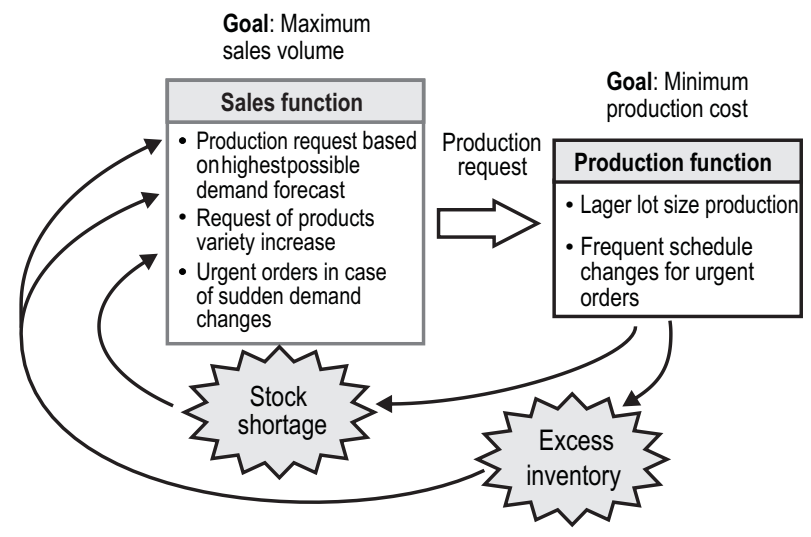

\section{Demand-To-Supply Management Problem}

In a stable demand situation, independent strategies of the sales function and the production function can result in profit optimization. However, in today's unstable and unforeseeable market situation, local optimization in each function may lead to loss of sales opportunities and increased inventory costs (Matsui et al., 2006). To make a rational demand-to-supply management strategy from a corporate-wide standpoint and to increase profit in today's unstable and unforeseen market situation, demand-to-supply management in which both sales and production functions work together with sharing information, as shown in Figure 2, is necessary.

As shown in Figure 2, a collaborative demand-tosupply management strategy is made based on information from the sales function and the production function. The strategy is fed back to the sales function and the production function to update each function's strategy and to form each function's plan. Most companies have recognized the importance of demand-to-supply management strategy in today's market situation. However, the sales function and the production function still do not collaborate well with each other (Matsui and Fujikawa, 2005). In addition, research and practice do not sufficiently provide tools and methodologies applicable to collaborative demand-to-supply management.

Enterprise Resource Planning (Monk and Wagner, 2008), for example, has spread widely for corporate core information systems since the middle of the 1990's. ERP is a type of software application which fully integrates core business functions, including transaction processing, management information, etc. Most ERP packages, for example, can apply financial management, human resource management, marketing, sales, production management, etc. However, most ERP packages do not include the concept of demand-to-supply management. Although they are useful for integration of corporate information, they have almost no mechanism for collaborative decision making among different functions.

Based on these circumstances, Matsui et al. (2006) propose a demand-to-supply management planner, the planner, using the strategic map which shows performance for each combination of sales and production strategies. The strategic map is developed using the concept of a pair-matrix table (Matsui, 2002). Matsui et al. (2007) modify the planner so that the planner is applicable to long-term business planning, and it demonstrates the effectiveness of the application in a case study. In this paper, we expand the planner in order to select a better strategy using production scheduling. In addition, we develop a training and education system for staff of sales and production functions to educate demand-to-supply management using the planner. 
Figure 2. A two function model of the collaborative demand-to-supply problem

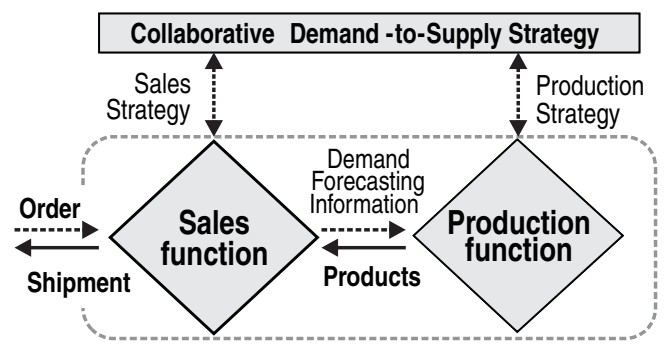

\section{Overview of Demand-To-Supply Management Planner}

The planner, which we developed for collaborative demand-to-supply management, works to find a demand-to-supply plan which maximizes profit, called expected net return ( $E N)$. It consists of six major steps as shown in Figure 3. Namely, the planner forecasts future demand based on the historical demand data in certain periods, and it designs a demand-to-supply strategic map (called the strategic map). The strategic map (Matsui, 2009) is a 2dimensional matrix consisting of a demand strategy axis and a supply strategy axis, as explained in section 4.2 in this paper. The design of the strategic map defines the ranges of both axes. Aggregate planning makes an aggregate plan which minimizes the expected cost $(E C)$ of each combination of strategies. Because the expected return (ER), defined by the demand level is already determined on the strategic map, the $E N$ is obtained as $E N=E R-E C$. Then the planner selects a demand-to-supply plan, which maximizes the $E N$ from the map. (The demand-to-supply plan selected is hereafter referred to as "the plan.") The plan is evaluated with production scheduling (Morton and Pentico, 1993) under more detailed production conditions from a production capacity standpoint. After the evaluation, the planner modifies production capacity or scheduling parameters to improve the accuracy of the plan if necessary. The planner also evaluates the plan by progressive analysis from an inventory level standpoint to determine the potential directions for collaborative work between both functions. The planner repeats aggregate planning, scheduling, and evaluation steps until an acceptable demand-to-supply plan for both the sales function and the production function is created.

In the planner, demand forecasting is considered as a step to reflect the strategy of the sales function. On the contrary, aggregate planning and scheduling are considered as steps to reflect the strategy of the production function. The strategic map is used to compare the strategies of both functions and to determine the optimum plan.

In the following sections, functions and methodologies used in the planner are explained in detail.

\subsection{Demand Forecasting}

The demand forecasting step in the planner forecasts the monthly demand of the target products based on historical demand data. In the current version, the planner uses the exponential smoothing method for demand forecasting. The numerical formula of the method is shown in section 4.1. It is possible to take different demand forecasting approaches in the planner by modifying the design of the strategic map.

Figure 3. Steps of the demand-to-supply management planner

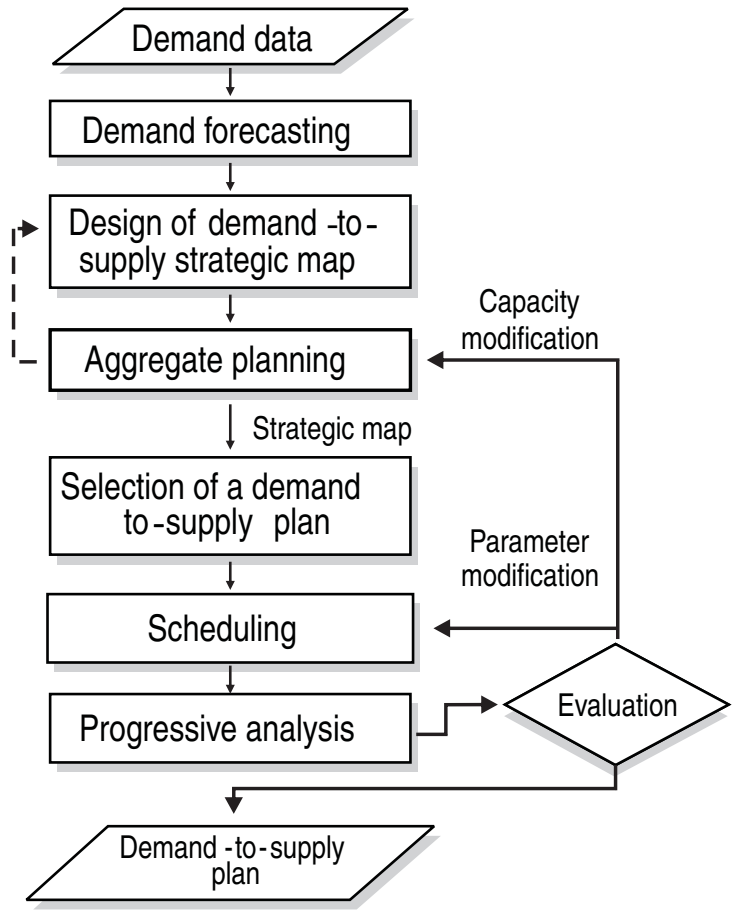




\subsection{Design of Demand-to-Supply Strategic Map}

The strategic map represents the possible combinations of sales strategies and production strategies, as shown in Figure 4 . The map consists of a row for expected demand, which is considered to be the strategy of the sales function, and a column for the smoothing factor of the exponential smoothing method, which is considered to be the strategy of the production function. In the strategic map, each cell, which indicates the crossing point of a row and a column, shows the performance indices, including $E N, E R, E C$, and expected lead time at $N$ inventory level $\left(E T\left(N^{*}\right)\right)$. The mathematical models to obtain these indices are shown in detail in section 4.1 .

\subsection{Aggregate Planning}

Aggregate planning calculates production quantities for each month using linear programming, which minimize $E C$, including the production cost, inventory cost, back order penalty cost, and the cost of idle resources. The monthly production quantity is provided by demand forecasting. The numerical formula to obtain an aggregate plan is shown in section 4.1 .

Figure 4. Example of strategic map

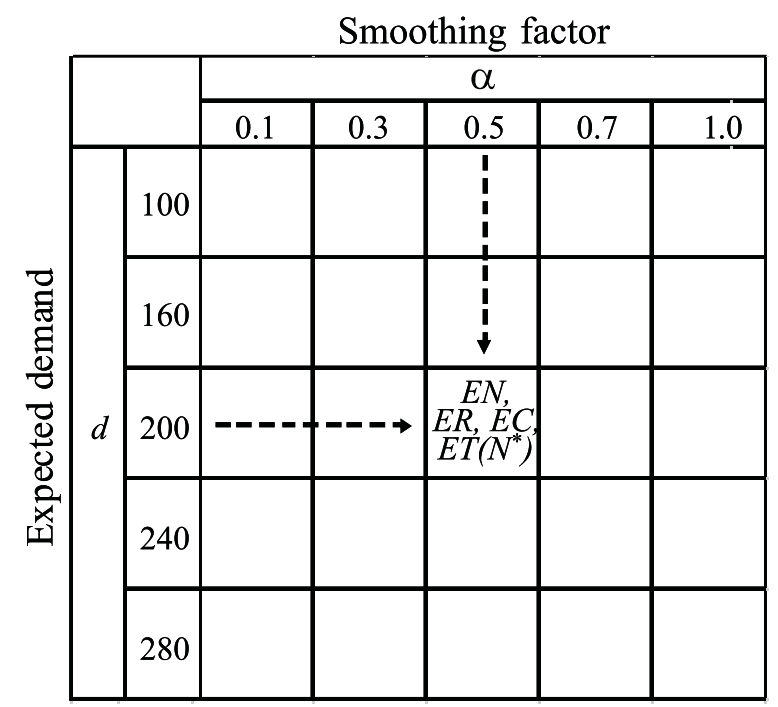

\subsection{Selection of a Demand-to-Supply Plan}

In this step, the planner selects the optimum plan, i.e. the one with the highest EN, from the strategic map. The strategic map is made using the results of the aggregate planning. The detailed steps to make the strategic map are shown in section 4.2 .

In the planner, the strategic map plays a role to evaluate possible combinations of strategies by sales and production functions. The strategic map visualizes the value of objective functions as a matrix in order to determine the optimum combination of sales strategy and production strategy, as shown in Figure 4.

\subsection{Scheduling}

The scheduling step simulates the plan, selected from the strategic map, under detailed production conditions, including production sequence, machine speed, production lot size, number of products and production volume of each product, setup time, overtime work, etc. Based on the results of the scheduling, the planner rebuilds the strategic map if the expected production capacity is significantly different than the aggregate planning conditions.

The planner assumes that the results of the scheduling indicate the actual production capacity under the current production conditions. Therefore, the planner replaces parameters for aggregate planning to make a more accurate strategic map (Wang, 2007). Scheduling enables us to examine the plan selected from a strategic map under detailed production conditions, and to make a more accurate plan by comparing the results of the scheduling to those of the plan.

\subsection{Progressive Analysis}

In the planner, progressive analysis is used to compare the plans obtained by aggregate planning and scheduling. Progressive analysis, which is an application of progressive-curve-based control (Usuki et al., 2001), graphically depicts the cumulative figures of input to and output from the production system. Using the figure, we can analyze the work in process, order fulfillment time, and their fluctuations. Namely, in the planner, progressive analysis allows us to evaluate the plans and to find methods for improving the accuracy of the strategic map. 


\section{Model of the Planner}

\subsection{Mathematical Model}

Objective functions at the sales function and the production function, i.e. - $E R$ and $E C$, respectively, are optimized mathematically based on strategic parameters of each function. EN is obtained by ER and $E C$. The relationship of the objective function and strategic parameters is given as Equation (1). In this equation, $N, d$, and $\alpha$, respectively stand for standard inventory level, expected demand quantity, and smoothing factor at the demand forecasting step. In addition, $E R$ is given by Equation (2).

$$
\begin{array}{r}
E N(N, d, \alpha)=E R(d, \alpha)-E C(N, d, \alpha) \rightarrow \max \\
E R=\sum_{t=1}^{T} P_{t} D_{t} / T \rightarrow \max
\end{array}
$$

In Equation (2), $T$ stands for the planning horizon. $D_{t}$ stands for the forecasted demand at $t^{\text {th }}$ period, which is obtained from historical demand data $d_{t}$ and $\alpha$ by Equation (3). In addition, $P_{t}$ stands for the price at $t^{\text {th }}$ period, which is obtained by Equation (4).

$$
\begin{array}{r}
D_{t}=\alpha d_{t}+(1-\alpha) D_{t-1} \quad(0 \leq \alpha \leq 1) \\
P_{t}=P_{0}+\frac{P_{0}\left|d_{0}-d\right|}{b \rho d_{0}}
\end{array}
$$

In Equation (4), $P_{0}, d_{0}, \rho, b$, stands for, respectively, standard price, standard demand quantity, rate of utilization, and price elasticity, which refers to the sensitivity of demand when the price changes.

$E C$ is expressed as Equation (5), and is obtained using linear programming by setting Equation (5) as the objective function. Constraints to the objective function are given in Equations (6) and (7). Table 1 describes the nomenclature of each equation.

$$
\begin{aligned}
E C=\sum_{t=1}^{T} & \left\{c_{1} X_{t}+c_{2} Y_{t}+c_{3} Z_{t}+c_{4} I_{t}\right. \\
& \left.+c_{5} B_{t}+c_{6}\left(X_{\max }-X_{t}\right)\right\} / T \rightarrow \min
\end{aligned}
$$

$$
\begin{gathered}
I_{t}-B_{t}=I_{t-1}-B_{t-1}+X_{t}+Y_{t}+Z_{t}-D_{t} \\
X_{t} \leq X_{\max }, \quad Y_{t} \leq Y_{\max }, \quad Z_{t} \leq Z_{\text {max }}
\end{gathered}
$$

The objective function (5) can be modified as (8) to add the condition on $N$. Namely, in the objective function (8), penalty costs are defined on the gap between $I_{t}$ and $N$.

$$
\begin{aligned}
E C= & \sum_{t=1}^{T}\left\{c_{1} X_{t}+c_{2} Y_{t}+c_{3} Z_{t}=c_{4} N+\right. \\
& \left.c_{7}\left(L_{t}-N\right)^{+}+c_{8}\left(N-L_{t}\right)^{=}\right\} / T \rightarrow \min
\end{aligned}
$$

s.t. $\left(L_{t}=I_{t}-B_{t},(a)^{+}=\max (0, \mathrm{a}), c_{7}\right.$ means penalty cost when $L_{t}$ is larger than $N$, and $c_{s}$ means penalty cost when $L_{t}$ is smaller than $N$ ). In addition, $E T$ per year is defined in Equation (9).

$$
E T=\left\{\sum_{t=1}^{12}\left(I_{t}-B_{t}\right) / D_{t}\right\} / T
$$

Table 1. Explanation of variables and constraints

\begin{tabular}{|l||l|}
\hline \multicolumn{1}{|c|}{ Variables } \\
\hline \hline$X_{t}$ & Regular production quantity \\
\hline$Y_{t}$ & Overtime work production quantity \\
\hline$Z_{t}$ & Outsourcing production quantity \\
\hline$I_{t}$ & Inventory at the end of the $t^{\text {th }}$ period \\
\hline$B_{t}$ & Back order quantity \\
\hline & \\
\hline$C_{1}$ & Cost of regular production \\
\hline$C_{2}$ & Cost of overtime work production \\
\hline$C_{3}$ & Cost of outsourcing production \\
\hline$C_{4}$ & Inventory keeping cost \\
\hline$C_{5}$ & Back order cost (penalty) \\
\hline$C_{6}$ & Cost of idle resource \\
\hline$I_{0}$ & Inventory at the beginning of the planning \\
\hline$X_{\max }$ & Capacity of regular production \\
\hline$Y_{\max }$ & Capacity of overtime work production \\
\hline$Z_{\max }$ & Capacity of outsourcing production \\
\hline
\end{tabular}




\subsection{Steps for Making the Strategic MAP}

The strategic map, as shown in Figure 4, is a matrix consisting of the smoothing factor of the exponential smoothing method and expected demand. The smoothing factor relates to fluctuation of production volume at each period, therefore it affects the capacity of the production function. Simplified steps for making the strategic map are shown in Figure 5.

In the first step, demand data as well as the minimum and the maximum values of $\alpha, d$, and $N$ are defined. Then the values at equal intervals between the minimum and the maximum of $\alpha, d$, and $N$, which defined the number of columns and rows of the strategic map, are initiated, respectively. The strategic map represents indices consisting of $E N, E R, E C$, and $E T$ for all the combinations of $\alpha, d$, and $N$. The number of intervals of $\alpha$ and $d$ define the amount of detail of the strategic map. The values of $\alpha$ and $d$ are set as each minimum value at the beginning, and are increased at each iteration of the steps as shown in Figure 5. EN, ER, $E C$, and $E T$ for each combination of $\alpha$ and $d$ are

Figure 5. Steps for making the strategic map

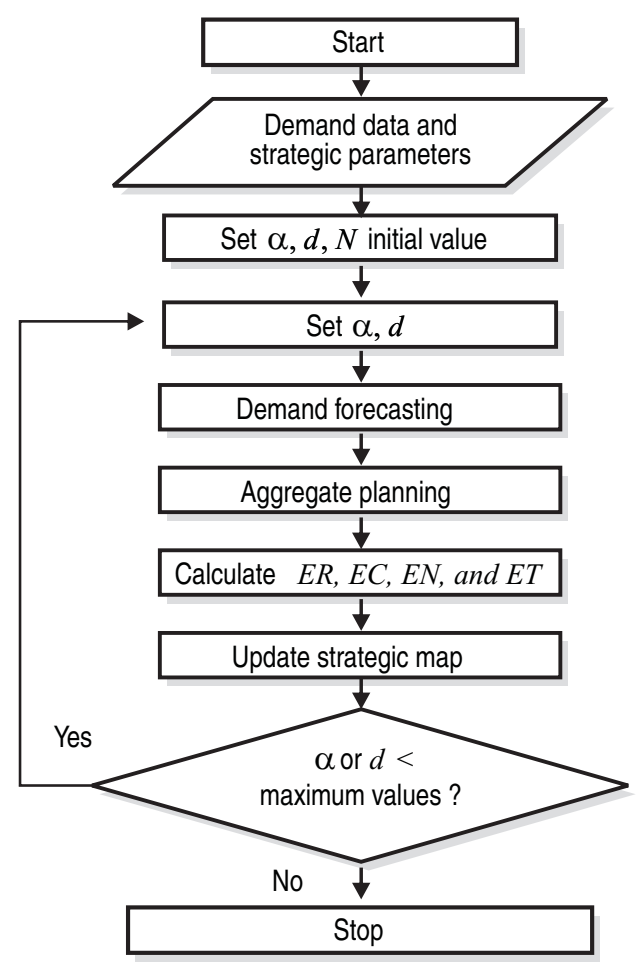

calculated based on demand forecasting and the aggregate planning. The strategic map, therefore, is made in a step-by-step fashion by changing the combination of $\alpha$ and $d$. In each combination of $\alpha$ and $d$, the strategic map shows $E R, E C, E T$, and $E N$ at $N^{*}$, which indicates the inventory level resulting in the maximum $E N$.

\section{A Numerical Example of the Planner}

In this section, we demonstrate a numerical example of the planner.

Table 2 shows standard demand data for 12 planning periods in this example. In demand forecasting, historical data are adjusted by Equation (3), and the average demand is set to the expected demand $(d)$. In this example, we define $\alpha$ from 0.1 to 1.0 with increments of $0.1, d$ from 100 to 280 with increments of 20, and $N$ from 40 to 200 with increments of 20. Therefore there are 900 strategies consisting of the combination of $\alpha, d, N$, in this example. In addition, Table 3 shows the constants for linear programming to obtain the optimum aggregate plan based on each combination of $\alpha$ and $d$.

Table 2. Demand data

\begin{tabular}{|c|c|c|c|}
\hline $\boldsymbol{t}$ & $\boldsymbol{d}_{\boldsymbol{1}}$ & $\boldsymbol{t}$ & $\boldsymbol{d}_{\mathbf{1}}$ \\
\hline 1 & 284 & 7 & 314 \\
2 & 268 & 8 & 253 \\
3 & 253 & 9 & 275 \\
4 & 252 & 10 & 264 \\
5 & 271 & 11 & 238 \\
6 & 325 & 12 & 292 \\
\hline
\end{tabular}

Table 4 shows the aggregate plan selected as the optimum plan using linear programming. The combination of $\alpha, d$, and $N$ on the selected plan are as follows:

Smoothing factor $(\alpha)$ : 0.6 ,

Expected demand $(d): 200$,

Normal inventory quantity $(N): 40$.

The forecasted demand $\left(D_{t}\right)$ in Table 4 is less than the value shown in Table 2 because the planner adjusts demand data in accordance with $d$. 
Table 3. Constants for linear programming

\begin{tabular}{|c|c|c|c|}
\hline Constant & Value & Constant & Value \\
\hline$C_{1}$ & 100 & $P_{0}$ & 130 \\
$C_{2}$ & 107 & $d_{0}$ & 270 \\
$C_{3}$ & 115 & $b$ & 2 \\
$C_{4}$ & 5 & $I_{0}$ & 0 \\
$C_{5}$ & 270 & $X_{\max }$ & 200 \\
$C_{6}$ & 80 & $Y_{\max }$ & 20 \\
$C_{7}$ & 200 & $Z_{\max }$ & 30 \\
$C_{8}$ & 300 & & \\
\hline
\end{tabular}

Figure 6 shows a part of the strategic map obtained in this example. As shown in Figure 6, the maximum $E N$ is located between the minimum EC and the maximum ER. This phenomenon is called the ellipsecross theory (Matsui, et al., 2006), which usually appears in the strategic map. This theory is useful for identifying the methods to improve the demand-tosupply management strategy.

After an aggregate plan is selected, the scheduling step examines the plan under detailed production conditions. The planner modifies the plan based on the results of scheduling, if necessary, to improve the accuracy of the plan. Figure 7 shows the model for scheduling in this example. In the model, the production system makes two kinds of products by lot production. Setup time is required at any production process to change the kind of product. In this example, we set the lot size as 5 units per lot, and the setup time as 120 minutes per process.

In the current version of the planner, we use ASPROVA (http://www.asprova.jp/) as a production scheduler. ASPROVA is a commercial based scheduler employed world-wide. It can build a scheduling model based on practical conditions, as well as provide scheduling algorithms to solve complex scheduling problems. Therefore the planner can be applied to complex production systems in practical problems.

The differences between the scheduling and the aggregate plan are visualized by progressive curves, as shown in Figure 8. In the figure, the result of the scheduling indicates that the aggregate plan, in fact, does not have enough production capacity to supply products. The scheduling step evaluates several scenarios to increase production capacity. For example, Figure 9 shows the inventory as the result of the scheduling step. In this case, the production system at the 1st scheduling does not have enough capacity to satisfy the demand, therefore it cannot keep the standard inventory level. In this situation, the overtime work capacity is expanded to provide the supply capacity with enough to satisfy the demand. The result of the scheduling after changing the capacity is shown as the 2nd scheduling in Figure 9.

The plans obtained from the strategic map and from the scheduling can be different because production conditions in scheduling are more detailed than that of the plans in the strategic map. For example, production lot size, variety of product, and setup time are not considered in the plans for the strategic map. Therefore the planner feeds back the results of the scheduling to the aggregate planning in order to rebuild the strategic map, if necessary. The feedback information is production capacity, referred to as the maximum regular production volume available per period, in consideration of lot size, frequency of setup, etc. (Hayashi, 2007).

Table 4. The aggregate plan selected by the planner

\begin{tabular}{|r|c|c|c|c|c|c|}
\hline $\boldsymbol{t}$ & $\boldsymbol{D}_{\boldsymbol{t}}$ & $\boldsymbol{X}_{\boldsymbol{t}}$ & $\boldsymbol{Y}_{\boldsymbol{t}}$ & $\boldsymbol{Z}_{\boldsymbol{t}}$ & $\boldsymbol{I}_{\boldsymbol{t}}$ & $\boldsymbol{B}_{\boldsymbol{t}}$ \\
\hline 1 & 194 & 200 & 34 & 0 & 40 & 0 \\
2 & 195 & 195 & 0 & 0 & 40 & 0 \\
3 & 189 & 189 & 0 & 0 & 40 & 0 \\
4 & 186 & 186 & 0 & 0 & 40 & 0 \\
5 & 193 & 193 & 0 & 0 & 40 & 0 \\
6 & 219 & 200 & 19 & 0 & 40 & 0 \\
7 & 225 & 200 & 25 & 0 & 40 & 0 \\
8 & 201 & 200 & 1 & 0 & 40 & 0 \\
9 & 201 & 200 & 1 & 0 & 40 & 0 \\
10 & 196 & 196 & 0 & 0 & 40 & 0 \\
11 & 183 & 183 & 0 & 0 & 40 & 0 \\
12 & 201 & 200 & 1 & 0 & 40 & 0 \\
\hline sum & 2382 & 2342 & 81 & --- & --- & 0 \\
\hline \hline
\end{tabular}


Figure 6. A part of the strategic map

\begin{tabular}{|c|c|c|c|c|c|c|}
\hline$d$ & $\alpha$ & 0.1 & 0.3 & 0.6 & 0.8 & 1 \\
\hline \multirow{5}{*}{100} & $E R$ & 23643.17 & 24828.5 & 25167.17 & 25336.5 & 25421.17 \\
\hline & $E C$ & 18128.33 & 18221.67 & 18248.33 & 18261.67 & 18268.33 \\
\hline & $E N$ & \multirow{2}{*}{\multicolumn{2}{|c|}{$0.0 C \min$}} & 6918.833 & 7074.833 & 7152.833 \\
\hline & $E T$ & & & 0.405199 & 0.403156 & 0.40295 \\
\hline & $N^{*}$ & 40 & 40 & 40 & 40 & 40 \\
\hline \multirow{5}{*}{160} & $E R$ & 6938.83 & 20181.25 & 28763.92 & 28854.42 & 28960 \\
\hline & $E C$ & 19243.33 & 193967 & $E_{1} 1443 \mathrm{mi}$ & Q 19455 & 19510.17 \\
\hline & $E N$ & 7695.5 & 8889.53 & 9318.917 & 9399.417 & 9449.833 \\
\hline & $E T$ & 0.260012 & 0.2565 & 0.252597 & $\theta_{252258}$ & 0.251962 \\
\hline & $N^{*}$ & 40 & 40 & 40 & 40 & 40 \\
\hline \multirow{5}{*}{200} & $E R$ & 29016 & 30459 & \multirow{2}{*}{\multicolumn{2}{|c|}{$E N_{\max }$}} & 31226 \\
\hline & $E C$ & 20109.92 & 20497.92 & & & -21195.4 \\
\hline & $E N$ & 8906.083 & 9961.083 & 10153.42 & 10103.42 & 10030.58 \\
\hline & $E T$ & 0.215266 & 0.205261 & 0.202114 & 0.201576 & 0.201379 \\
\hline & $N^{*}$ & 40 & 40. & 40 & 40 & 40 \\
\hline \multirow{5}{*}{240} & $E R$ & 31255 & $32795^{4}$ & 33343.33 & 33471.67 & 3363.33 \\
\hline & $E C$ & 23052.42 & 24251.42 & 84699.83 & 2481058 & 2495183 \\
\hline & $E N$ & 8202.583 & 8543.583 & 8643.5 & 8655.08 & 86713 \\
\hline & $E T$ & .0 .179353 & 0.171088 & 0.168535 & 0.168217. & 167874 \\
\hline & $N^{*}$ & 40 & 40 & 40 & 40 & 40 \\
\hline \multirow{5}{*}{280} & $E R$ & 33322.67 & 34986.67 & 35552 & 35722.67 & 35829.33 \\
\hline & $E C$ & 27201.67 & 28696.67 & 29196.67 & 29948.75 & \multirow[b]{2}{*}{$E R_{\text {max }}$} \\
\hline & $E N$ & 6121 & 6290 & 6355.333 & 6373.97 & \\
\hline & $E T$ & 0.153802 & 0.146626 & 0.139326 & 0.138526 & Q131074 \\
\hline & $N^{*}$ & 40 & 40 & 40 & 40 & $40=$ \\
\hline
\end{tabular}

Figure 7. A model of scheduling

(Production lot size: 5 unit/lot, Setup time per resource: 120 minutes)

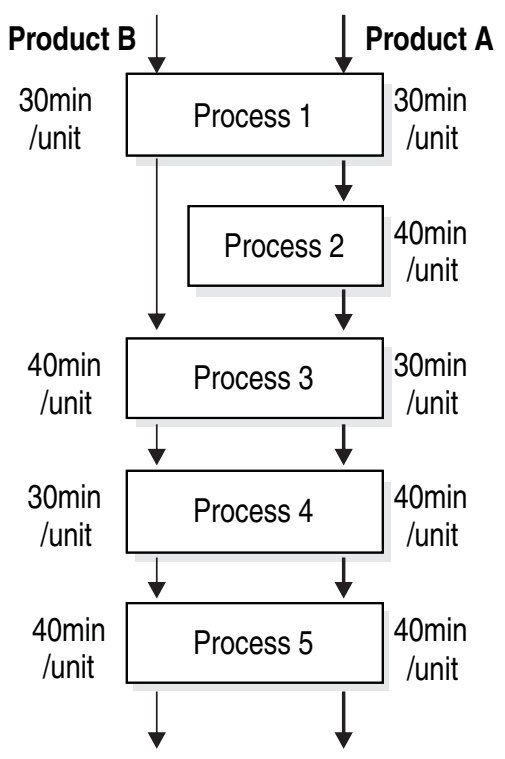

Figure 8. Progressive curve

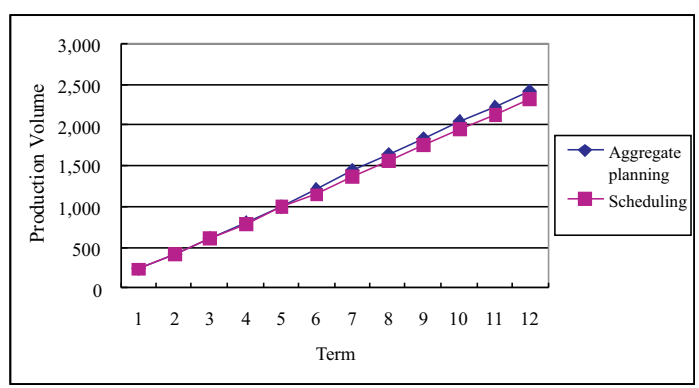

Figure 9. Change of inventory at scheduling step

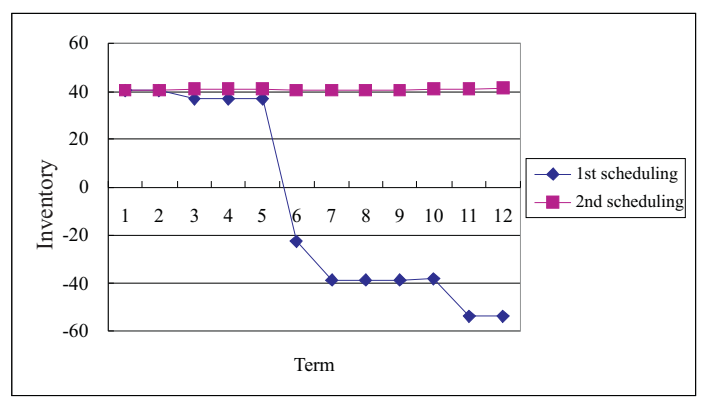

\section{An Education System for Demand-to-Supply Management}

In this section, we describe an education system for demand-to-supply management as well as an application of the planner in the system. The planner is used as a learning tool to support exercises in the education system. As shown in section 6.3, the planner is a useful tool to understand the effectiveness of demand-to-supply management.

\subsection{Background}

As stated in chapter 1, demand-to-supply management plays an important role in establishing a sustainable company. In practice, however, it is usually the case that the sales function and the production function work individually for their own respective goals without realizing the importance of collaborative decision making, and therefore profit optimization and sustainability improvement of a company are not always attained. As Simon et al. (2006) stated, a market share-driven approach, which takes strategies for improved sales volume, revenue growth, and therefore increased market share, is still recognized as 
a good practice in most companies, even in the SCM age.

Under these circumstances, in order to improve profit and sustainability, it is necessary to train skilled staff who can successfully establish demand-to-supply management in the company. For this reason, companies request an education system that considers the characteristics of demand-to-supply management (Hayashi et al., 2008). In addition, well established education systems in any company, in general, are effective in improving sustainability. For example, the balanced scorecard (Kaplan and Norton, 1992) emphasizes the learning and growth perspective as one of the four general perspectives as performance measures for corporate innovation.

Based on the above background, we have developed an education support system to teach the basis of collaborative demand-to-supply management.

\subsection{Overview of the Education System}

The education system described in this paper is designed for students including undergraduate students, graduate students, and corporate staff who are in charge of demand-to-supply management. In the education system, different goals are set based on the skill and knowledge of students as shown in Table 5. The highest level of the goals is level 5 .

Figure 10 shows a framework of the education system consisting of educational goal setting and a study course, which itself consists of a series of lectures, exercises, and measurements for evaluation, as well as exercise support software and evaluation methods of the effectiveness of the education. The evaluation section examines the effectiveness of the education system based on the results of measurements through a series of lectures and exercises. The results of the evaluation are used to improve the effectiveness of the system.

Table 6 describes the course design in the system (Sakashita, 2008). In the lectures, students study the essential concepts and necessary knowledge of demand-to-supply management, such as the demandto-supply problem, demand forecasting, production planning, scheduling, inventory management, logistics, SCM, and examples of collaborative demand-to-supply management in several industries.

Through the exercises, students gain knowledge and comprehension of demand-to-supply management. The exercises consist of two parts. In the first part, students gain skills for scheduling by solving sample scheduling problems. In the second part, students study demand-to-supply management through a group exercise. In the group exercise, demand groups and supply groups are formed. The number of groups depends on the size of the class. Each student belongs to one of the two groups. In the exercise, conditions for the case study are provided. The case is selected depending on the knowledge and

Table 5. Goals of the education for each student level (U: Undergraduate student G: Graduated student C: Corporate staff)

\begin{tabular}{|c|c|c|c|c|}
\hline \multirow{2}{*}{ Level } & \multirow{2}{*}{ Goal of Education } & \multicolumn{3}{|c|}{ Student } \\
\hline & & $U$ & G & C \\
\hline 1 & $\begin{array}{l}\text { Understand the current business environment as well as } \\
\text { of the collaborative demand-to-supply management necessity }\end{array}$ & Y & Y & Y \\
\hline 2 & $\begin{array}{l}\text { Understand technical terms on demand-to-supply } \\
\text { management }\end{array}$ & Y & Y & Y \\
\hline 3 & $\begin{array}{l}\text { Be able to explain the steps and mechanisms of profit } \\
\text { maximization by collaborative demand-to-supply management }\end{array}$ & Y & Y & Y \\
\hline 4 & $\begin{array}{l}\text { Be able to apply collaborative demand-to-supply management } \\
\text { to simple problems }\end{array}$ & - & Y & Y \\
\hline 5 & $\begin{array}{l}\text { Be able to apply the collaborative demand-to-supply } \\
\text { management to practical problems }\end{array}$ & - & - & Y \\
\hline
\end{tabular}


Figure 10. A framework of the education system

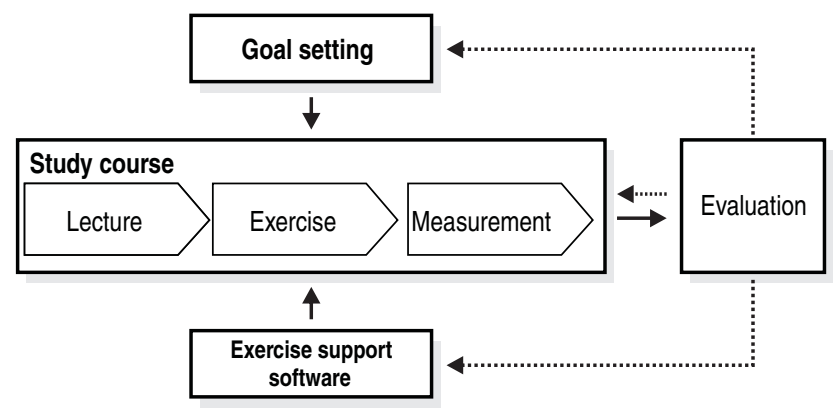

Table 6. An example of course design

\begin{tabular}{|c|c|c|}
\hline 1 & Lecture (1) & Introduction to demand-to-supply management \\
\hline 2 & Lecture (2) & $\begin{array}{l}\text { Steps and mechanisms of demand-to-supply } \\
\text { management }\end{array}$ \\
\hline 3 & Exercise & Fundamental operations of production scheduler \\
\hline 4 & $\begin{array}{l}\text { Group } \\
\text { exercise (1) }\end{array}$ & $\begin{array}{l}\text { Selection of a demand strategy and a supply strategy } \\
\text { separately in each demand group and supply group } \\
\text { using the planner }\end{array}$ \\
\hline 5 & $\begin{array}{l}\text { Group } \\
\text { exercise (1) }\end{array}$ & $\begin{array}{l}\text { Selection of a demand-to-supply strategy in } \\
\text { collaboration with demand group and supply group }\end{array}$ \\
\hline
\end{tabular}

skill of students. Figure 11 shows the steps of the group exercise. The demand group makes a demand plan which maximizes sales, and the supply group makes a supply plan which minimizes production cost based on the production conditions of the case study. After planning, the demand group and the supply group exchange their plans with each other, and examine the differences between the plans. In addition, a demand group and a supply group work together to find an optimum plan which makes maximum profit. The planner is used as a software tool to make plans through exercises.

The series of exercises plays a role in providing students with experience in collaboration. Namely, it is expected that the exercises help students gain knowledge and skills of demand-to-supply management. In addition, the effectiveness of the course is measured through questionnaires and interviews with students. Students answer questionnaires before and after the course, therefore it is possible to compare the answers and to evaluate the effectiveness of the course.
Figure 11. Steps of group exercise

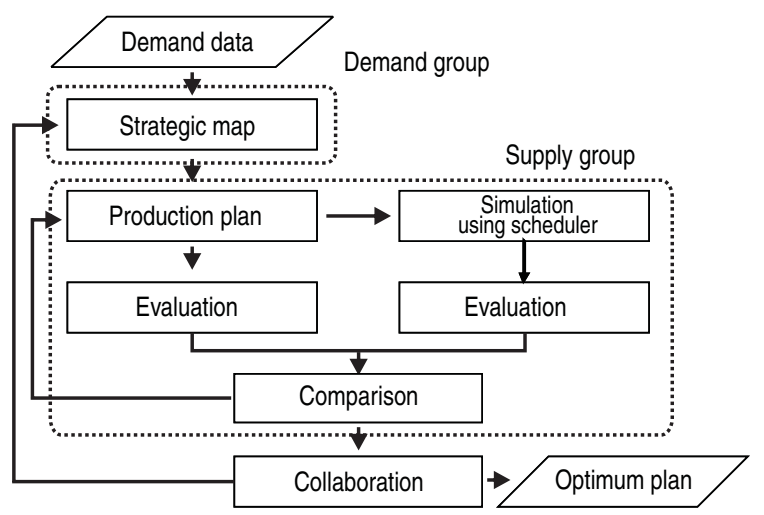

\subsection{Results of a Trial Class}

We instructed a trial class of graduate students in order to evaluate the effectiveness of the proposed education system. Figure 12 compares the answers to questionnaires before and after taking the course for the trial class. The questionnaires ask about fundamental knowledge to be learned through the course. In Figure 12, the upper rows of each category indicate the answers before taking the course. The lower rows, on the other hand, indicate the answers after taking the course. In addition, each row shows the degree of understanding for each category. The right side bars indicate a higher understanding level. Therefore the difference between the upper row and the lower row shows the effectiveness of the education system. In this case, we can say that most students improved their understanding through the course. However, improvement of understanding cannot be observed in several categories, such as progressive analysis. We should reform lectures and exercises in such areas in order to improve the effectiveness of the education system.

\section{Future Development}

One of the goals of demand-to-supply management is to improve corporate sustainability under today's uncertain and unforeseeable market conditions. The overall framework of demand-to-supply management is depicted in Figure 13. The planner described in this paper covers a part of the short-term strategic perspective of the framework. The system for the mid- 
Figure 12. Evaluation of effectiveness of education system
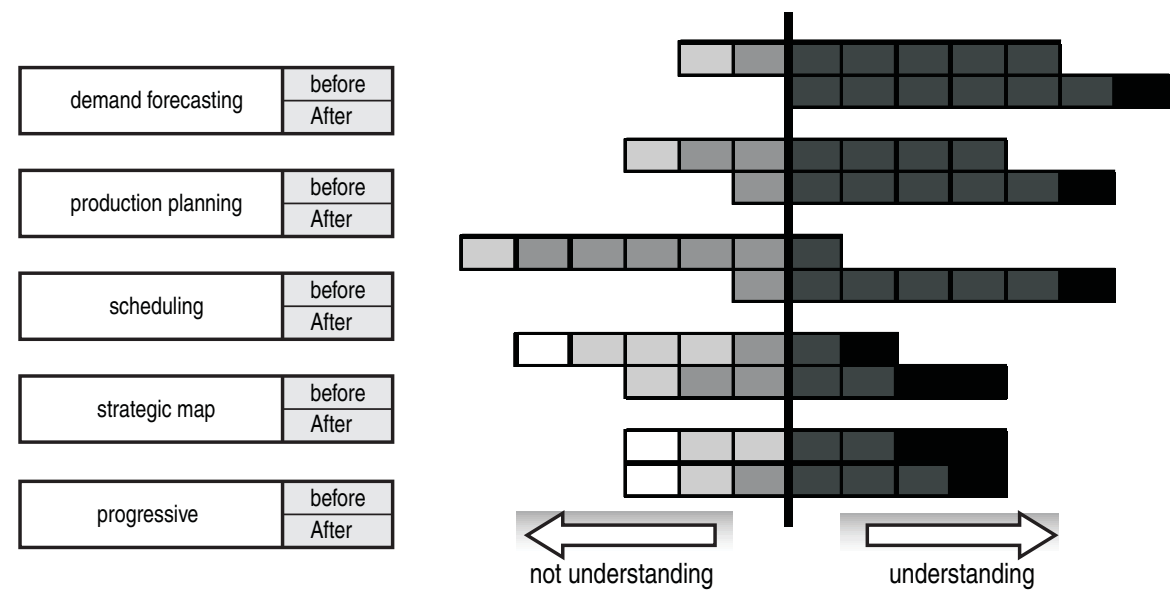

term strategic perspective creates a supply system plan including capacity expansion, outsourcing, etc. It also creates a demand development plan including marketing strategy, pricing strategy, etc, in order to improve corporate profit. In the long-term strategic perspective, on the other hand, business life cycles based on core products should be considered. Every business has a life cycle. Every company must decide the right withdrawal time from the market of matured products in every product case. The system for the long-term strategic perspective supports decisions for product release and revision as well as decisions for products portfolio management to improve corporate sustainability.
In future research and development, the systems of long-term and mid-term strategic perspectives should be developed. In addition, the planner should be integrated with those systems in order to improve corporate sustainability. Regarding the planner, flexibility should be increased to make it more applicable in practice to more diverse demand-tosupply problems. For example, a generalized strategic map which is applicable to many demand forecasting methods needs to be developed. In addition, methodologies of progressive analysis need to be improved. Progressive analysis evaluates the plan and indicates methods to improve the plan. Therefore, methodologies used in progressive analysis are critical

Figure 13. An overall framework for demand-to-supply management for a sustainable company

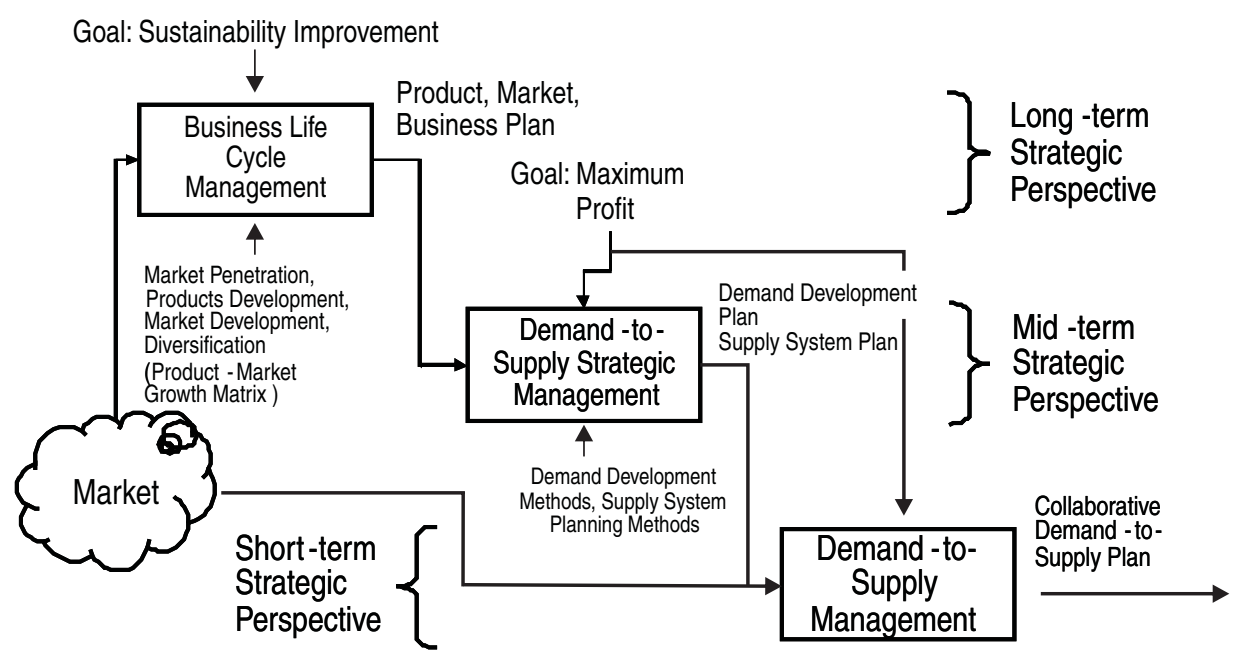


to find the optimum plan using the planner. Regarding the education system, more trial classes are required to evaluate the effectiveness of the system. These classes should especially be applied so that corporate staff can evaluate the system from the point of view of several practitioners. In addition, more case studies should be prepared to increase the variety of exercises.

\section{Conclusions}

In the SCM age, companies are exposed to severe competition more than ever before. In this situation, collaborative demand-to-supply management described in this paper is a critical issue in establishing a sustainable company. In most cases, however, the sales function and the production function do not always work together to make an optimum plan. In other words, collaborative demand-to-supply management has not been well established in most companies. In this paper, we described a framework of demand-to-supply management and the planner, which is a software tool used in the framework for supporting collaborative demand-to-supply management. In addition, we propose an education system to gain knowledge and skills for collaborative demand-to-supply management as an application of the planner. In this paper, we show the effectiveness of the system based on the results of a trial class. We also describe the potential areas of future research and development of demand-to-supply management and the planner.

\section{References}

Cyber Concurrent Management Research Group (2004). Cyber-Manufacturing:e-Learning Lessons, Aoyama Gakuin University Research Institute AML II Project, Tokyo.

Hayashi, A. (2007). Development of improved demand-to-supply planner. Graduation Thesis of Department of Systems Engineering, The University of ElectroCommunications.

Hayashi, A., Ishii, N., and Matsui, M. (2008). Development and preliminary evaluation of a learning system on demand-to-supply management for sustainable corporate management. Journal of International Association of Project E Program Management, 3 (1), pp. 5160.
Kaplan R. S. and Norton, D. P. (1992). The balanced scorecard: measures that drive performance. Harvard Business Review, (January-February), pp. 71-79.

Matsui, M. (2002). A management game theory: economic traffic, leadtime and pricing setting. Journal of Japan Industrial Management Association, 53 (1), pp. 1-9.

Matsui, M. (2009). Manufacturing and Service Enterprise with Risks, Springer, New York.

Matsui, M. and Fujikawa, H. (2005). Selling and manufacturing can collaborate profitably. Diamond Harvard Business Review, (January), pp.72-83.

Matsui, M., Nakamura, T., and Ishii, N. (2007). A demand-tosupply development system for sustainable business strategies and a case study. Journal of Japan Industrial Management Association, 58 (4), pp.307-316.

Matsui, M., Takahashi, Y., and Wang, Z. (2006). A construction and theory of the manager-aided planner for collaborative demand and supply. Journal of Japan Industrial Management Association, 57 (2), pp. 120-131.

Monk, E. F. and Wagner, B. J. (2008). Concepts in Enterprise Resource Planning, Third edition, Course Technology, Boston.

Morton, T. E. and Pentico, D. W. (1993). Heuristic Scheduling Systems: with Applications to Production Systems and Project Management, Wiley-Interscience, NY.

Sakashita, K. (2008). Development of education support system with demand-to-supply planner and scheduler. Graduation Thesis of Department of Systems Engineering, The University of Electro-Communications.

Simchi-Levi, D., Kaminsky, P., Simchi-Levi, E. (2007). Designing and Managing Supply Chain, Irwin McGrawHill, NY.

Simon, H., Bilstein, F. F., and Luby, F. (2006). Manage for Profit, not for Market Share, a Guide to Greater Profit in Highly Contested Markets, Harvard Business School Press, Boston.

Usuki, J., Kitaoka, M., and Matsui, M. (2001). Cumulative control problems and grey-theoretic model. Bulletin of The University of Electro-Communications, 14, pp. 13-20.

Wang, Z. (2007). Strategic direction of demand-to-supply planner, Master's Thesis in Department of Systems Engineering, Graduate School of ElectroCommunications, The University of ElectroCommunications. 
Akihiko Hayashi is a graduate student in Department of Systems Engineering, Graduate School of ElectroCommunications, The University of Electro-Communications. He received a Bachelor of Engineering Degree from The University of Electro-Communications in 2007. His email address is <ahayashi@se.uec.ac.jp>

Nobuaki Ishii is an Associate Professor in Department of Information Systems, Faculty of Information and Communication, Bunkyo University, Japan. He received a Doctor of Engineering Degree in Industrial Engineering and Management from Tokyo Institute of Technology, Japan. He was a visiting scholar at Purdue University, 19891990. His research interests include supply chain management, project management, and information systems management. He is currently a director of the society of project management. His email address is $<$ ishii@shonan.bunkyo.ac.jp>

Masayuki Matsui is a Professor in the Department of Systems Engineering at The University of ElectroCommunications. He received a BS and MS in Industrial Engineering from Hiroshima University, and DEng. in research on conveyor-serviced production systems from Tokyo Institute of Technology, Japan. He was a visiting scholar at UC Berkeley and Purdue University, 1996-1997. His recent research interests are industrial engineering, production and operation management, and management theory, operations research, quality management, artificial intelligence. He published in Journal such as IIE Transaction, International Journal of Production Research, International Journal of Production Economics, Production Planning and Control, International Journal of Productivity and Quality Management, Industrial Engineering and Management Systems, Computers and Industrial Engineering Journal, International Journal of Flexible Manufacturing Systems, Assemble Automation, Journal of the Operations Research Society of Japan, Journal of Japan Industrial Management Association, Journal of Japan Society of Logistics Systems. He was the editor of JIMA journal (2003-2007), is a Senior Member of IIE, and is a Member of JIMA and ORSJ in Japan. Recently, he was given JIMA Award and JIMA Paper Award, and is now JIMA president, and the board member of International Federation of Production Research (IFPR). His email address is <matsui@se.uec.ac.jp> 